\title{
O Tempo e o (E)vento: efeitos do tempo e do vento das mudanças em traduções de autobiografias de escritores afro-americanos
}

\author{
Time and the Wind (ow of the Event): the effects \\ of time and the wind of changes in translations of \\ autobiographies by African-American writers
}

Lauro Maia Amorim*

\section{RESUMO}

A tradução de autobiografias é tema pouco investigado nos Estudos da Tradução. Este trabalho pretende fazer uma contribuição analisando traduções de duas autobiografias de escritores afro-americanos: Black boy, de Richard Wright (1908-1960) e I know why the caged bird sings, de Maya Angelou (1928-2014), tendo, como parâmetro de reflexão, os efeitos que a passagem do tempo acarreta para o processo tradutório. Concebida seja por um/uma escritor(a), poeta, musicista ou outro(a) profissional, a autobiografia parece supor a existência prévia de obras (ou atuações) que fizeram do seu/sua autor(a) uma figura célebre. Diferentemente do romance, a autobiografia, pressuporia um compromisso com a "verdade", já que supostamente retrataria eventos que seu/sua próprio(a) autor(a) teria vivido, o que a distanciaria, em tese, da condição de ficcionalidade. Observa-se o papel que o tempo exerce sobre o fazer autobiográfico (em vista da diferença entre o presente da enunciação no ato de narrar e o passado que se busca rememorar pela linguagem), bem como sobre o processo de reenunciação promovido pela tradução, impactada pela passagem do tempo que a separa do texto original. As análises indicam a construção de uma expressividade própria nas traduções, por meio da qual cada uma reimagina o "real" autobiográfico em português.

Palavras-chave: Tradução; Autobiografia; Tempo; Literatura Afro-Americana.

\footnotetext{
* Professor Assistente Doutor do Departamento de Estudos Linguísticos e Literários e do Programa de Pós-Graduação em Estudos Linguísticos (linha de pesquisa: Estudos da Tradução) da Universidade Estadual Paulista (Unesp), Instituto de Biociências Letras e Ciências Exatas (Ibilce), Câmpus São José do Rio Preto.
} 
Amorim, L. M.

O Tempo e o $(E)$ vento: efeitos do tempo e do vento das mudanças em traduções de autobiografias de escritores afro-americanos

Revista Letras, Curitiba, UFPR, n. 95 84-108, jan./jun. 2017. ISSN 2236-0999 (versão eletrônica)

\begin{abstract}
The translation of autobiographies has been scarcely investigated in Translation Studies. This paper intends to contribute to analyzing translations of two autobiographies by African-American writers: Black boy, by Richard Wright (1908-1960), and I know why the caged bird sings, by Maya Angelou (1928-2014), by considering the effects that the passage of time has on translation. Conceived either by a writer/poet/musician or other professional, an autobiography seems to imply the previous existence of works or actions that turned its author into a celebrity. Unlike a novel, an autobiography would imply a commitment to "truth" as it allegedly portrays events the author has supposedly gone through, which, in theory, distances it away from the condition of fictionality. This paper draws on the role that time plays on the autobiographical making (in view of the differences between the present condition of enunciation during the author's act of narrating and the quest for the past when remembering takes place embedded in language), as well as on the renunciation undertaken by translation, which is impacted upon by the passage of time that sets it apart from the source text. The analysis suggests that the translations have built their own way of expression, whereby each one reimagines the autobiographical "real" in Portuguese.
\end{abstract}

Keywords: Translation; Autobiography; Time; African-American Literature. 


\footnotetext{
1. relação entre tempo e tradução é um tema particularmente instigante $\Delta$ quando se observam diferenças linguísticas e de interpretação que revelam gênero literário, como a autobiografia, envolve uma recontextualização temporal, e de que maneira traduções de autobiografias de autores afro-americanos indicam opções que refletem valores ideológicos e/ou linguísticos oriundos de épocas distintas. Faremos uma breve introdução sobre as características definidoras da autobiografia e, em seguida, partiremos para um contraste entre textos originais e traduzidos envolvendo o seguinte corpus literário autobiográfico:
}

a) Black boy, de Richard Wright (1945/2009), e duas traduções: Negrinho, traduzido por Wilson Velloso (Editora Companhia Nacional, 1946), a tradução Black boy, realizada por Aurora Maria Soares Neiva (Editora Espaço e Tempo, 1993).

b) I know why the caged bird sings, de Maya Angelou (1969/2010), e uma tradução: Eu sei porque o pássaro canta na gaiola, realizada por Paula Rosas (Editora José Olympio, 1996). 
Amorim, L. M.

O Tempo e o $(E)$ vento: efeitos do tempo e do vento das mudanças em traduções de autobiografias de escritores afro-americanos
A autobiografia é um gênero literário que converge para si valores contrastantes. Por um lado, tende a desfrutar de grande popularidade, especialmente porque, na maioria das vezes, é um produto editorial associado a um/uma autor(a) de notável reconhecimento público (pelo menos à época da sua publicação). Muito raramente se vê uma autobiografia escrita por um/ uma autor(a) absolutamente desconhecido. Nesse sentido, a autobiografia, concebida seja por um/uma escritor(a), poeta, músico ou outro(a) profissional, parece supor a existência prévia de obras ou atuações que fizeram do seu/sua autor(a) uma figura célebre. Por outro lado, comparativamente ao romance e à poesia, a autobiografia é tradicionalmente vista como um gênero "menor", não gozando do mesmo espaço de que aqueles gêneros dispõem no universo acadêmico. É considerada "menor" porque a autobiografia, diferentemente do romance, pressuporia um compromisso com a verdade, já que seu objetivo maior seria retratar a vida que seu/sua autor(a) teria vivido, o que faria dela um objeto de estudo de menor interesse, pois nela estaria ausente, em tese, a condição de ficcionalidade.

Além disso, ao se deparar com uma obra que se apresenta como uma autobiografia, o/a leitor(a) é levado(a) a supor, com base em convenções mais ou menos implícitas, que o narrador dessa obra seria o/a próprio(a) autor(a) (o que não se supõe em um romance, por exemplo). É partindo dessa diferença que Lejeune (2008) propõe uma definição econômica para autobiografia:

Em oposição a todas as formas de ficção, a biografia e autobiografia são textos referenciais exatamente como o discurso científico ou histórico, eles se propõem a fornecer informações a respeito de uma "realidade" externa ao texto e a se submeter portanto a uma prova de verificação. Seu objetivo não é a simples verossimilhança, mas a semelhança com o verdadeiro. Não o "efeito de real", mas a imagem do real. Todos esses textos referenciais comportam então o que chamarei de pacto referencial, implícito ou explícito, no qual se incluem uma definição do campo real visado e um enunciado das modalidades e do grau de semelhança aos quais o texto aspira. (p. 36)

No contexto inicial de seus escritos, na década de 1970, Lejeune considerava o "pacto autobiográfico" um elemento essencial para que uma autobiografia tivesse os efeitos pretendidos com sua publicação. Assim, esse pacto supõe, por exemplo, a identidade de nome entre autor, narrador e personagem, a qual pode se dar de forma implícita ou explícita. De maneira implícita, essa relação pode ser estabelecida, por exemplo, com o uso de títulos ou afirmações que sugerem que se trata de uma autobiografia (como, por exemplo, "Minha história”, etc). Esse pacto também pode ser inferido quando, na seção inicial do
Revista Letras,

Curitiba, UFPR, n. 95 84-108, jan./jun. 2017. ISSN 2236-0999 (versão eletrônica) 
texto, o narrador assume um compromisso com o leitor, "comportando-se como se fosse o autor, de tal forma que o leitor não tenha nenhuma dúvida quanto ao fato de que o 'eu' remete ao nome escrito na capa do livro, embora o nome não seja repetido no texto" (p.27). A relação de identidade entre o nome do autor e o narrador também pode ser apresentada de maneira explícita quando há uma coincidência inequívoca entre o narrador-personagem da própria narrativa e o nome do autor impresso na capa.

Partindo do que seria "o grau mínimo" de ficcionalidade até chegar ao ponto máximo da presença de dispositivos de natureza ficcional, Lejeune (2008) distingue dois tipos de pacto: o pacto autobiográfico e o pacto romanesco. Para o teórico, "o pacto autobiográfico é a afirmação, no texto, dessa identidade [autor-narrador-personagem], remetendo, em última instância, ao nome do autor, escrito na capa do livro" (p.26). Contrastivamente, no polo oposto do pacto autobiográfico, o pacto romanesco vale-se de dois aspectos: "[a] prática patente da não-identidade (o autor e o personagem não têm o mesmo nome) e [o] atestado de ficcionalidade" (Lejeune, 1998, p. 27). Esse atestado, segundo o teórico, é garantido pelo subtítulo "romance", informação geralmente oferecida, na atualidade, na capa ou na folha de rosto dos livros.

Posteriormente, no texto "O Pacto Autobiográfico (Bis)", Lejeune (2008) reconsidera, até certo ponto, sua definição do pacto, ao responder às críticas que recebera por ter estabelecido fronteiras conceituais muito rígidas para a autobiografia em oposição a outros gêneros literários. Assim, o teórico busca, nesse segundo texto, considerar novos aspectos que apontem para a variabilidade de que se constituem os valores atribuídos às autobiografias no espaço de certas convenções. Pode-se resumir essa nova postura de Lejeune com as seguintes observações feitas por ele:

1. O que chamo autobiografia pode pertencer a dois sistemas diferentes: um sistema referencial "real" (em que o compromisso autobiográfico, mesmo passando pelo livro e pela escrita, tem valor de ato) e um sistema literário, no qual a escrita não tem pretensões à transparência, mas pode perfeitamente imitar, mobilizar as crenças do primeiro sistema. Muitos fenômenos de ambiguidade ou de mal-entendido vêm dessa posição instável.

2. Em relação ao autor, pode haver defasagem entre sua intenção inicial e a intenção que lhe será atribuída pelo leitor, seja porque o autor desconhece os efeitos induzidos pelo modo de apresentação que escolheu, seja porque entre ele e o leitor existem outras instâncias: muitos elementos que condicionam a leitura (subtítulo, classificação genérica, publicidade, adendo) 
Amorim, L. M.

O Tempo e o $(E)$ vento: efeitos do tempo e do vento das mudanças em traduções de autobiografias de escritores afro-americanos podem ter sido escolhidos pelo editor e já interpretados pelos meios de comunicação.

3. Enfim, é preciso admitir que podem coexistir leituras diferentes do mesmo texto, interpretações diferentes do mesmo "contrato" proposto. O público não é homogêneo. Os diferentes editores, as diversas coleções se dirigem a públicos que não são sensíveis aos mesmos signos, nem julgam segundo os mesmos critérios. No "Pacto", minha tendência foi considerar-me como representativo do "leitor médio" e, consequentemente, transformei minhas reações de leitura em norma. (p. 57)

Esse "contrato" de leitura em torno das autobiografias poderá ser entendido de modo diferente pelo(a) leitor(a). Nos casos das traduções de autobiografias aqui analisadas, os tradutores, como leitores intermediários, serão os primeiros a reforçar ou, até certo ponto, relativizar, o contrato ou o pacto que se estabelece entre a oferta, feita pelo(a) autor(a), do "real" ou da "suposta" verdade atribuída ao/à autobiografado(a), e a expectativa dos leitores em conhecer essa verdade. Ressalta-se, porém, que essa expectativa em conhecer a verdade não é um dado puramente a priori, já que também é resultado das imagens que a editora constrói acerca do(a) autobiografado(a), o que poderá, certamente, ter um impacto no modo como o/a tradutor(a) e o/a editor(a) entendem que a autobiografia deva ser apresentada ao/à leitor(a) final.

Em vista das convenções com as quais a grande maioria dos leitores está acostumada, a presença do nome do(a) tradutor(a) não parece alterar, de modo significativo, as expectativas e pressupostos acerca de uma autobiografia traduzida. De modo geral, esses leitores não são informados pelas reflexões contemporâneas que não consideram a tradução como um mero reflexo direto, transparente ou sem mediação de um texto estrangeiro, reflexões essas que concebem a tradução como uma forma de transformação regulada (DERRIDA, 2001) ou como um tipo de reescrita constituída de refrações linguísticas, culturais e ideológicas (LEFEVERE, 2007). Embora seja inegável que a concepção de tradução como atividade mecânica de transposição de significados entre línguas ainda seja um dado do senso comum, na prática, como ressalta Darin (2014), o texto estrangeiro não permanece inócuo às transformações empreendidas na tradução, mesmo que elas sejam aparentemente insignificantes aos olhos de quem compara o texto de partida com o de chegada. O texto autobiográfico traduzido, portanto, será uma mescla de vozes que indicam a interferência (indesejável ou não, mas inevitável) da polifonia:

Quanto a nós, preferimos celebrar o espaço da reconfiguração, refração e diferença, do texto como um coro de tons e melodias

Revista Letras,

Curitiba, UFPr,

n. 95 84-108, jan./jun. 2017. ISSN 2236-0999 (versão eletrônica) 
diversificados, simultâneos, afins e divergentes. Optamos por invocar a polifonia de BAKHTIN (2008: 309) e desvelar na autobiografia e na tradução a resistência ao discurso autoral, ao padrão monódico da voz que quer se sobrepor, guiar, reduzir, castrar. A ação do escritor, do biógrafo, do tradutor e do leitor são camadas adicionais que se interpenetram e fundem, formando textos caleidoscópicos e ruidosos, onde há lugar para todos. (DARIN, 2014, p. 81)

\section{Tradução e autobiografias de escritores afro-americanos: as relações entre tempo e reenunciação}

\subsection{O caso de Black boy: a record of childhood and youth, de Richard Wright (1945)}

Richard Wright (1908-1960) é um dos autores mais celebrados da literatura afro-americana do século XX, sendo reconhecido principalmente por sua obra mais influente, o romance Native Son, publicado em 1940, e pela primeira vez, no Brasil, em 1941, com a tradução de Monteiro Lobato. Além de ter tido uma vasta produção literária, teatral e ensaística, Wright também ficou conhecido por suas relações com o partido comunista norte-americano e por suas reflexões sobre o racismo. Native Son foi identificado como um romance de protesto que veio dividir opiniões e criar polêmicas, justamente por apresentar Bigger Thomas, o protagonista, como um homem violento, insensível e insubordinável. Foi criticado por muitos, especialmente pela comunidade negra, por ter supostamente "confirmado" o estereótipo de violência atribuído aos negros pela sociedade branca. Mas o autor respondeu a essa crítica afirmando que a própria sociedade racista produzia as condições suficientes para a proliferação de muitos "Bigger Thomas". A autobiografia Black Boy, contendo quatorze capítulos, veio a público em 1945, sendo, na realidade, uma obra que inicialmente deveria ter sido publicada como American Hunger, contendo os primeiros quatorze capítulos sobre a infância e adolescência do autor no Sul, seguidos de mais seis capítulos sobre sua fase adulta em Chicago. No entanto, para que pudesse ser publicada pelo Book-of-the-Month-Club, a editora exigiu a exclusão da segunda parte da autobiografia. Assim, a versão "incompleta", intitulada Black Boy, é a que serviu de referência para a publicação, em 1946, pela Editora Companhia Nacional, da tradução realizada por Wilson Velloso, e intitulada Negrinho: recordações da infância e da juventude. Uma nova tradução, Black boy: infância e juventude de um negro americano, feita por Aurora Maria Soares Neiva, seria publicada, em 1993, pela editora Espaço e Tempo. 
Amorim, L. M.

O Tempo e o $(E)$ vento: efeitos do tempo e do vento das mudanças em traduções de autobiografias de escritores afro-americanos
Diferentemente do que Lejeune (2008) previa inicialmente, a primeira tradução no Brasil, de 1946, da autobiografia de Black boy não parece criar um vínculo direto e inequívoco entre o autor da obra e a sua relação com a autobiografia. Não há, seja na capa do livro, na $4^{\text {a }}$. capa ou mesmo na folha de rosto, qualquer afirmação como "autobiografia, "memórias" ou "narrativa autobiográfica”, nem mesmo a presença de um resumo introdutório sobre Richard Wright (explicando quem ele era). Há, porém, uma breve nota introdutória de conteúdo diverso, na qual se lê o seguinte:

Há mais de oitenta e cinco anos, Oliver Wendell Holmes disse, nobremente: "É muito mais fácil destinar uma alma à perdição ou orar pela sua salvação do que assumir a responsabilidade por lhe haver permitido desenvolver-se a esmo e no caminho da ruína. Só nos fins do século dezoito é que a lei inglesa começou a admitir a ideia de que o crime não é necessariamente um pecado. As limitações da responsabilidade humana jamais foram corretamente estudadas".

Se o dr. Holmes fosse vivo, teria orgulho - como eu tenho - de poder concorrer para chamar a atenção raciocinante dos americanos inteligentes e moralmente responsáveis para esta história sincera, terrivel, lancinante, da infância e da juventude de um negro, traçada pelo dom raro do escritor Richard Wright.

Dorothy Canfield Fisher

(WRIGHT, 1946, p.07, grifos meus)

Como se pode observar, a obra não é apresentada claramente, de modo inequívoco, como uma autobiografia. Cria-se a percepção de que o livro poderia ser lido como uma versão ficcionalizada, já que a última afirmação da nota introdutória não cria uma ligação supostamente objetiva e cristalina entre o autor e o narrador em $1^{\text {a }}$. pessoa. O livro, assim, é apresentado de maneira, no mínimo, ambígua, sendo possível que o leitor seja levado a adquirir o livro porque trata da vida de uma criança negra nos Estados Unidos, e não, necessariamente, da vida de um escritor negro em ascensão. O protagonista chama-se Richard (tal como o autor), o que pode, certamente, levar o leitor a compreender, conforme prossegue com a leitura, que o personagem principal é o próprio autor do livro. Nesse sentido, é possível que o leitor, àquela época da tradução, tenha chegado à conclusão de que se tratava de uma autobiografia, por um processo de pressuposição não imediato, ocorrido com a observação indireta da relação entre o nome do autor e o nome do protagonista/narrador em $1^{\mathrm{a}}$. pessoa.

O que poderia explicar a ausência dessa relação mais imediata entre autor e narrador que a maioria das autobiografias parece implicar de modo quase "natural"? Em grande medida, os aspectos paratextuais do livro são fundamentais

Revista Letras,

Curitiba, UFPR,

n. 95 84-108, jan./jun. 2017. ISSN 2236-0999 (versão eletrônica) 
no sentido de fortalecer essa relação, mas isso não ocorre nessa versão. Richard Wright, tendo tido sua obra mais famosa, Filho Nativo, publicada no Brasil apenas em 1941, não chegou, em 1946, a ser uma figura artística conhecida dos brasileiros, uma vez que a autobiografia foi publicada apenas cinco anos após a publicação de Filho Nativo. Embora não haja dúvidas de que a referida obra seja efetivamente uma autobiografia, a editora - consciente da ausência, por parte do público, de um conhecimento mais sólido acerca do nome (e do capital simbólico) do autor —, recorreu a uma "saída" comercial mais favorável ao publicar a obra de forma que não suscitasse, de maneira explícita, a sua condição de narrativa autobiográfica. Uma das principais razões pelas quais uma autobiografia pode ser um sucesso comercial é justamente a sua vinculação a um autor minimamente conhecido pelo público que se pretende alcançar. E essa vinculação, em 1946, parecia praticamente impossível.

Em 1993, a difusão do nome de Richard Wright, no Brasil, já estava consolidada, especialmente com a publicação da segunda tradução de Filho Nativo, em 1987, e também com um número maior de ensaios e trabalhos de pesquisa sobre o autor nas universidades. A dimensão temporal aqui é crucial: a consolidação do seu nome permitiu que a autobiografia de 1993 pudesse ser publicada com o título inglês (supondo que muitos leitores seriam capazes de compreendê-lo). Essa opção reflete também a busca por um tom politicamente menos incorreto em comparação à tradução de 1946, cujo título, Negrinho, parece pouco aceitável em tempos marcados pela consciência multiculturalista.

Além disso, na $4^{\text {a }}$. capa, a editora da retradução apresenta um trecho do prefácio, assinado por John Reilly, no qual este descreve os apuros e sofrimentos pelos quais o menino Richard Wright viveu em uma família cujos laços afetivos eram tênues, senão ríspidos e alienantes, numa sociedade profundamente racista. A tradução mais recente assume, assim, desde a capa e a contracapa, a condição de Black boy como autobiografia.

Trechos das duas traduções serão comparados para que possamos demonstrar de que modo as linguagens dessas versões são, por um lado, testemunhas do papel que o tempo desempenhou sobre a perspectiva interpretativa dos seus tradutores e, por outro, de que modo contribuíram para a construção de uma imagem discursiva mais ou menos coerente com o princípio demarcatório da narrativa autobiográfica. Para tanto, alguns trechos foram selecionados de acordo com certos critérios semântico-ideológicos, estilísticos ou sociolinguísticos para facilitar a discussão.

\section{a) O efeito do tempo e a mediação tradutória na descrição/ construção do "real"}

No trecho abaixo, Richard se põe a refletir sobre suas origens e, especialmente, sobre quem efetivamente fora seu pai e o lugar que ocupara em sua vida (já que havia sido abandonado por ele): 
Amorim, L. M.

O Tempo e o $(E)$ vento: efeitos do tempo e do vento das mudanças em traduções de autobiografias de escritores afro-americanos

\section{Texto Original}

From far beyond the horizons that bound this bleak plantation there had come to me through my living knowledge that my father was a black peasant who had gone to the city seeking life, but who had failed in the city; a black peasant whose life had been hopelessly snarled in the city, and who had at last fled the city that same city which had lifted me in its burning arms and borne me toward alien and undreamed of shores of knowledge.

(ebook: 578)

Negrinho (Trad. de Wilson Velloso, 1946)

De muito além dos horizontes que cingiam aquela plantação erma me havia chegado, através da vida, a certeza de que meu pai era um camponês negro que fora para a cidade, desejando viver, mas que na cidade falhara; um camponês negro cuja vida à cidade emaranhara desgraçadamente e que por fim lhe fugira - à mesma cidade que me erguera nos seus braços de fogo e me conduzira a estranhas e mais sonhadas praias do saber.

(p.45, destaques meus)

Black Boy (Trad. de Aurora Soares Neiva, 1993)

De muito além dos horizontes que demarcavam aquela convicção de que o meu pai era um camponês negro que tinha se mudado para a cidade a procura de uma vida melhor, mas que tinha fracassado; um camponês negro cuja vida tinha se complicado terrivelmente na cidade, e que finalmente tinha fugido dela - aquela mesma vida que tinha me levantado em seus braços ardentes e me conduzido em direção a um mundo estranho e jamais sonhado de conhecimento.

(p.49-50, destaques meus)

O que chama mais a atenção, quando se comparam as traduções, é justamente o tom mais abstrato das afirmações destacadas na tradução de Velloso, em contraste com as descrições mais concretas sublinhadas na tradução de Neiva. Na primeira tradução, percebe-se a busca pela valorização de uma linguagem que soa menos mundana, ao contrário do que ocorre na segunda versão, mais próxima de uma descrição sem floreios ou sem associações incomuns. A tradução de Velloso parece criar o efeito descritivo dos fatos vividos de maneira menos transparente e mais mediada, o que pode ser observado em sua linguagem mais metaforizada ("braços de fogo"; "praias do saber"), com opções lexicais

Revista Letras,

Curitiba, UFPR,

n. 95 84-108, jan./jun. 2017. ISSN 2236-0999 (versão eletrônica) 
mais sofisticadas ("cingiam", “erma”, "emaranhara”, "erguera”) e formas verbais sintéticas ("fora", "falhara", "fugira").

A segunda tradução é menos metaforizada ("um mundo estranho e jamais sonhado de conhecimento"), tendendo para a veiculação do concreto, com um léxico menos sofisticado, e com formas verbais analíticas ("tinha fugido", "tinha me levantado"), com um efeito de maior fluência linguística, mais próximo da oralidade. A tradução de Soares Neiva sugere uma descrição dos fatos vividos de maneira mais "transparente" e aparentemente menos mediada, produzindo certo efeito "de realidade" frequentemente associado (embora não necessariamente) a uma linguagem "nivelada" que simula a descrição do ordinário, do que é comum. Nesse ponto, a segunda tradução sugere o fortalecimento de uma descrição mais "objetiva" em favor do efeito de "verdade" que se queira construir com o discurso autobiográfico.

Com a passagem do tempo, a imagem consagrada de Richard Wright se consolidou, de forma que, em tese, a segunda tradução parece ter sido atraída pelo efeito de realidade que o tempo presente (e o intervalo que o separa da primeira tradução) exerceu sobre a recepção da obra no Brasil mais atual, da década de 90, diferentemente da primeira tradução, que não contou com o devido espaçamento temporal intervalar, com a referida consolidação da imagem pública do autor.

A linguagem mais despojada da tradução de Soares Neiva, com um tratamento mais direto dos acontecimentos, conduz mais rapidamente o/a leitor(a) aos eventos vividos, sendo estes, talvez, o dado que mais interessa aos leitores que desejam conhecer a vida de um grande escritor, já reconhecido internacionalmente. As opções tradutórias de Velloso, contrastivamente, acentuam a "ficcionalização", não necessariamente dos "fatos" vividos, mas da linguagem por meio do qual esses fatos são rememorados.

\section{b) A passagem do tempo e o "politicamente correto"}

No trecho abaixo, Richard descreve seu primeiro contato com um barco a vapor, ao fazer uma viagem a Memphis com sua mãe. A realidade parece desapontar o garoto que sonhara com outra imagem. E, no segundo trecho, fala de suas brincadeiras com as crianças do bairro:

\section{Texto Original}

Solace came when I wandered about the boat and gazed at Negroes throwing dice, drinking whisky, playing cards, lolling on boxes, eating, talking, and singing (ebook: 179, destaques meus)

Of a summer morning [...] I would follow a crowd of black children - abandoned for the day by their working parents [...] 
Amorim, L. M.

O Tempo e o $(E)$ vento: efeitos do tempo e do vento das mudanças em traduções de autobiografias de escritores afro-americanos
Negrinho (Trad. de Wilson Velloso, 1946)

O consolo sobreviveu ao vaguear pelo barco e ver negros jogando dados, bebendo whisky, jogando baralho, largados indolentes, por cima de caixotes, comendo, falando e cantando.

(p. 18, destaques meus)

Nas manhãs de verão [...] eu ia com um bando de negrinhos - durante o dia abandonados pelos pais, que trabalham [...]

(p.28, destaques meus)

Black Boy (Trad. de Aurora Soares Neiva, 1993)

Só parei de chorar quando andei pelo barco todo e fiquei olhando atentamente uns negros jogando dados, bebendo uísque, jogando cartas, se refestelando em cima de umas caixas, comendo, conversando e cantando.

(pag. 20-21, destaques meus)

Nas manhãs de verão [...] eu seguia uma multidão de crianças negras - abandonadas durante o dia por pais que trabalhavam fora.

$$
\text { (p. 31, destaques meus) }
$$

É notável como as opções linguísticas de Velloso, tal como destacadas, parecem suscetíveis à crítica nos dias atuais. Ao descrever os trabalhadores negros jogando baralho, o tradutor enfatiza a indolência e o desleixo, mas a tradução não estaria em desacordo com os sentidos contextuais previstos pelo verbo "loll", como demonstra o dicionário Merriam-Webster', não sendo, portanto, incoerente com a leitura que o tradutor faz do trecho em inglês. Na verdade, em tempos de maior sensibilidade multiculturalista, que também inclui o período da tradução de Neiva, existe um esforço de se evitarem afirmações politicamente incorretas, particularmente aquelas que poderiam ser vistas como preconceituosas, de modo que a tradução de Neiva passa ao largo do julgamento do narrador, focalizando apenas o prazer derivado dos jogos e da bebida. O mesmo ocorre na segunda passagem, quando a frase "crowd of black children" encontra traduções sensivelmente diferentes no que tange à descrição das crianças.

\section{c) A passagem do tempo e a identificação racial}

$\mathrm{Na}$ passagem a seguir, Wright descreve uma professora que pagava aluguel para morar na casa de sua avó, em Jackson, capital do Mississipi:

1 "Loll -1. To hang loosely or laxly; 2. To act or move in a lax, lazy or indolent manner" (Disponível em: http://www.merriam-webster.com/dictionary/loll )
Revista Letras,

Curitiba, UFPR,

n. 95 84-108, jan./jun. 2017. ISSN 2236-0999 (versão eletrônica) 


\section{Texto Original}

To help support the household my grandmother boarded a colored schoolteacher, Ella, a young woman with so remote and dreamy and silent a manner that I was as much afraid of her as I was attracted to her.

(ebook: 609, destaques meus)

\section{Negrinho (Trad. de Wilson Velloso, 1946)}

Para ajudar na manutenção do lar minha avó dava pensão a uma professora de cor, Ella, uma moça de ar tão remoto, sonhador e silencioso que ao mesmo tempo eu the tinha medo e me sentia atraído.

(p. 48, destaques meus)

Black Boy (Trad. de Aurora Soares Neiva, 1993)

Para ajudar no orçamento da casa, minha avó alugava um quarto para uma professora, Ella, uma mulher jovem, mas tão distante, sonhadora e calada que o medo que ela me causava era tão grande quanto a atração que sentia por ela.

(p.53, destaques meus)

Segundo o dicionário Oxford, o adjetivo "colored" é utilizado para descrever "descendência não branca, total ou parcial”, sendo, porém, "atualmente considerado ofensivo nos Estados Unidos". 2 Assim, embora o termo "colored" possa estar associado à descrição de afrodescendentes, tanto de pele mais escura quando de tez mais clara (usado, nesse caso, em oposição à white), é possível que no trecho acima, "colored" esteja sendo empregado para descrever a professora negra com pele mais clara. À época em que a obra foi publicada, o termo "colored" não era necessariamente ofensivo, especialmente quando usado entre interlocutores negros. O dicionário Caudas Aulete registra que a expressão "de cor" refere-se à "pessoa de pele escura". ${ }^{3}$ No Brasil atual, essa expressão é vista como uma forma de eufemismo que pode beirar a ofensa. Na segunda tradução, não há qualquer referência objetiva em relação à cor da pele da professora, o que parece refletir, do ponto de vista ideológico, a busca tanto por uma descrição mais politicamente correta (e consonante com os novos tempos), quanto com uma forma de omissão que parece sugerir ao leitor, minimamente atualizado acerca das características sociais de uma nação racialmente segregadora, que seria improvável que uma professora branca alugasse um quarto na casa de uma

2 Disponível em: http://www.oxforddictionaries.com/definition/american_english/colored. No livro Black Talk, de Geneva Smitherman (2000, p.95), afirma-se que o termo "colored" ainda é empregado nos Estados Unidos, especialmente pelos idosos negros.

3 Disponível em: http://www.aulete.com.br/cor. 
Amorim, L. M.

O Tempo e o $(E)$ vento: efeitos do tempo e do vento das mudanças em traduções de autobiografias de escritores afro-americanos família negra: ou seja, ela só poderia ser negra (mesmo que fosse de pele mais clara). ${ }^{4}$ No trecho seguinte, Wright descreve sua avó:

\section{Texto Original}

My grandmother was as nearly White as a Negro can get without being white, which means that she was white.

(ebook: 634, destaques meus)

\section{Negrinho (Trad. de Wilson Velloso, 1946)}

Minha avó era quase tão branca quanto é possível a uma negra que não é branca; quer dizer, era branca.

(p. 50, destaques meus)

Black Boy (Trad. de Aurora Soares Neiva, 1993)

Minha avó tinha a pele tão branca quanto um negro poderia ter sem ser branco; isto é, ela era branca.

(p. 55, destaques meus)

Comparativamente, a tradução de Velloso se atém, quase literalmente, à formulação metafórica produzida no original. Já Soares Neiva introduz, na passagem, a palavra "pele", como forma de ajustar a comparação do narrador à perspectiva segundo a qual a cor da pele não altera, de modo significativo, a identidade negra da avó de Wright (pelo menos segundo os parâmetros raciais norte-americanos que, desde aproximadamente a década de 80 e 90, são cada vez mais difundidos no Brasil). Nesse sentido, Soares Neiva atualiza o texto original na tradução e, em comparação à de Velloso, é mais "desficcionalizante" na medida em que atenua a linguagem metafórica do original, aproximando-o de um registro autobiográfico de efeitos aparentemente mais "reais".

\section{d) A relação entre tempo e variação linguística}

No excerto abaixo, Wright se encontra na rua com outros garotos do bairro, os quais se divertem com as brincadeiras envolvendo flatulência:

\section{Texto Original}

“Hell, I ain't gonna stand near you, nigger” Pronouncement. $[\ldots]$

4 Não há dúvidas de que a omissão de “colored", em português, pressupõe, nesse contexto, uma concepção racial de negritude mais alinhada à tradição norte-americana segundo a qual não importa o grau de pigmentação da pele, mas sim a ascendência do indivíduo na categorização da sua identidade racial. Essa forma de categorização racial norte-americana têm adquirido cada vez mais solidez (ainda que não hegemônica) nas práticas de afirmação identitária no Brasil atual,

Revista Letras, o que se reflete na tradução da editora Espaço e Tempo.

Curitiba, UFPR,

n. 95 84-108, jan./jun. 2017. 
"Nigger, your mind's in a ditch." Amusingly moralistic.

"Ditch, nothing!" Nigger, you going to break wind any minute now!" Triumphant pronouncement creating suspense.

[...]

- The first white sonofabitch that bothers me is gonna get a hole knocked in his head!" Naïve rebellion.

(ebook: 1242-66, destaques meus)

\section{Negrinho (Trad. de Wilson Velloso, 1946)}

- Diabo, nun fico perto d'ocê, negro" - Pronunciamento.

[...]

- Crioulo, tua ideia anda sempre na sargeta. - Moralismo

divertido.

- Sargeta uma ova! Moleque, daqui a pouquinho ocê tá empestan'o ar! - Pronunciamento triunfante, criando expectativa.

$[\ldots]$

- O primeiro branco fiodaputa que me amolá a paciência vô fazê um buraco na cabeça dele! Rebelião ingênua.

(p. 90-2, destaques meus)

\section{Black Boy (Trad. de Aurora Soares Neiva, 1993)}

- Pô, não vou aguentar ficar perto de você não, seu crioulo!

- Declarando.

[...]

Todos da turma riem.

- Ô crioulo, tu só pensa em merda. - Expressando julgamento moral com tom de brincadeira.

- Merda, coisa nenhuma! Crioulo, tu vai soltar um peido daqui a pouquinho! - Declarando triunfantemente e criando suspense.

[...]

- O primeiro branco filho-da-puta que me azucrinar vai levar uma porrada na cabeça! - Revoltando-se ingenuamente.

$$
\text { (p.100-1, destaques meus) }
$$

Ao traduzir as formas de representação da oralidade consideradas não padrão do texto original, Velloso opta por uma variação linguística que, à época, 
Amorim, L. M.

O Tempo e o $(E)$ vento: efeitos do tempo e do vento das mudanças em traduções de autobiografias

de escritores afro-americanos era muito mais característica da zona rural. Lembrando que, em 1946, a maior parte da população brasileira não vivia nos perímetros urbanos, quadro esse que só começaria a mudar a partir da década de 70, com o aumento da população urbana, atualmente superando, de longe, os índices demográficos da população rural. ${ }^{5}$ Contrastivamente, a tradução de Soares Neiva expressa usos linguísticos típicos das grandes cidades, com foco especial nos dialetos populares do Rio de Janeiro (como no emprego de pronome sujeito "tu" seguido de formas verbais não conjugadas de acordo com o modelo normativo), diferentemente do que ocorre na tradução de Velloso, que parece indicar claramente uma variação dialetal mais interiorana. Assim, a tradução de Soares Neiva, por ser mais próxima das variações linguísticas urbanas atuais, parece criar um "efeito de realidade" maior que a tradução de Velloso, soando muito mais próxima dos registros orais (frequentemente oriundos do Rio de Janeiro) que a própria mídia, no Brasil, tende a reproduzir em novelas e seriados, em âmbito nacional, como "modelo" de comunicação, mesmo nos casos em que a variação linguística é considerada não padrão.

\subsection{Em dois tempos: I know why the caged bird sings, de Maya Angelou (1969/2010)}

Maya Angelou (1928-2014) é uma importante referência para a cultura e a história afro-americanas, tendo se destacado como escritora, atriz, roteirista, dançarina e poeta. Tornou-se inicialmente conhecida, na década de 50, com seus projetos musicais e coreográficos. Mais tarde atuaria como ativista no Movimento dos Direitos Civis, ao lado de Malcom X e Martin Luther King. Veio a se tornar a primeira mulher afro-americana a ter um roteiro produzido, tendo sido indicada para premiações por sua atuação como atriz na peça Look Away (1973) e na minissérie televisiva Roots (1977). Além de peças teatrais, e inúmeras coletâneas poéticas, publicou também várias autobiografias, sendo que I know why the caged bird sings, de 1969, é possivelmente a mais conhecida. Nessa obra, a autora relata as dificuldades e experiências traumáticas vividas na infância e adolescência, e a busca pela sua superação por meio da dignidade e da resistência à opressão racial.

\section{a) A relação entre a passagem do tempo e a identificação racial}

Ao descrever como seria sua mãe, que vivia na Califórnia, já que vivera até então apenas com sua avó, Marguerite (nome de infância de Angelou) consegue imaginá-la até mesmo em seu funeral:

5 Pode-se consultar essas informações demográficas no site do IBGE (incluindo a população rural e urbana, bem como o número de municípios criados desde 1960): http://www.censo2010. ibge.gov.br/sinopse/index.php? $\mathrm{uf}=00 \&$ dados $=1$
Revista Letras,

Curitiba, UFPR, n. 95 84-108, jan./jun. 2017. ISSN 2236-0999 (versão eletrônica) 


\section{Texto original}

Her hair, which was black, was spread out on a tiny little white pillow and her body was covered with a sheet. The face was brown $[. .$.

(ebook: 56, destaques meus)

\section{Tradução Paula Rosas - José Olympio Editora (1996)}

Seu cabelo, que era preto, estava espalhado sobre um minúsculo travesseiro branco e o corpo, coberto com um lençol. O rosto era marrom [...]

(p. 54, destaques meus)

Quando se trata de descrever, tradicionalmente, em língua portuguesa, a cor de pele, a palavra "marrom" não parece ser uma tradução muito frequente para "brown". ${ }^{6}$ A tendência mais corriqueira seria traduzir o termo por "moreno/a". Ao longo de toda a tradução, as ocorrências de "brown" como cor de pele são sistematicamente traduzidas por "marrom. Pode-se supor que ela reflita justamente a tentativa de se evitar a tradução por "moreno/a", já que, nas últimas décadas, os movimentos negros no Brasil têm manifestado uma crítica contundente a essa forma de descrição, especialmente porque ela tenderia a apagar a possível associação do indivíduo à identidade negra, já que uma pessoa morena pode ser tanto alguém de pele branca e cabelos pretos quanto alguém com pele negra, porém mais clara (muitas pessoas tendem, no Brasil, a identificar alguém com esse fenótipo como sendo "mulato" ou "mulata" - termos igualmente problemáticos do ponto de vista da afirmação da negritude em nosso país). Nesse sentido, o discurso multiculturalista das últimas décadas exerceu, assim, um impacto decisivo sobre o modo com que a tradutora e a editora entenderam qual deveria ser a cor do rosto aceitável, mesmo que isso pudesse acarretar alguma forma de estranhamento perante modos mais hegemônicos de se fazer essa identificação.

\section{b) O "não padrão" como forma de aproximação do passado pela reenunciação/rememoração}

No trecho a seguir, vemos a narradora reproduzindo as falas dos fregueses que frequentavam a mercearia da avó de Maya Angelou:

\footnotetext{
6 Em pesquisa realizada no site http://www.corpusdoportugues.org/web-dial/, que conta com corpora de 1 bilhão de palavras, foram obtidas 394 ocorrências para "pele morena" contra apenas 10 ocorrências para "pele marrom". Uma busca feita no Google confirmou o uso mais frequente para "pele morena" (541.000 ocorrências) contra aproximadamente 108 mil ocorrências de "pele marrom". Embora, como mostram os dados, o sintagma nominal "pele marrom" seja utilizado, o uso do adjetivo marrom para qualificar "rosto" (e não pele) é menos usual (1.970 ocorrências) quando comparado com "moreno" (23.100 ocorrências). Além disso, a busca revelou várias ocorrências com "rosto marrom" se referindo a contextos muito diferentes, como, por exemplo, "toalhas de rosto marrom", ou "cachorro preto com rosto marrom".
} 
Amorim, L. M.

O Tempo e o $(E)$ vento: efeitos do tempo e do vento das mudanças em traduções de autobiografias de escritores afro-americanos

\section{Texto original}

'Lemme have a hunk uh cheese and some sody crackers.' 'Just gimme a coupla them fat peanut paddies.'

(ebook: 09, destaques meus)

\section{Tradução Paula Rosas - José Olympio Editora (1996)}

- Me dê um naco de queijo e uns biscoitos.

- Me dê dois doces de amendoim.

(p. 16, destaques meus)

A criação das falas em inglês vernacular afro-americano representa a tentativa da autora de se aproximar do passado pela rememoração, de forma a produzir, na escrita, a realidade vivida como uma verdade simulada por meio da reenunciação. $\mathrm{Na}$ tradução, por outro lado, na medida em que não foi possível recriar a variação não padrão do inglês vernacular afro-americano, o leitor brasileiro é exposto tão somente a algumas leves variações linguísticas de natureza diafásica que apontam para certo coloquialismo (como, por exemplo, o emprego de pronome átono em início de período). O trecho em si não deixa de ser aceitável perante certa verossimilhança que ele tem com a representação da oralidade coloquial na escrita. O problema é que o efeito de reenunciação de um evento linguístico do passado, recriado para ser diferente do discurso corrente da autora no restante do livro, é apagado, de forma que as falas das freguesas da avó de Maya Angelou são assimiladas à fala da própria narradora, não havendo, portanto, uma diferença linguística simulada entre elas. Essa diferença é crucial do ponto de vista temporal, já que participa do processo de rememoração que reinventa o passado pela linguagem.

\section{c) A dimensão temporal e a percepção do "politicamente incorreto"}

No primeiro trecho abaixo, a narradora relata que as crianças negras que não respeitavam os adultos, chamando-os de "Mister", “ Miss", "Cousin”, etc, tornavam-se uma vergonha para os pais:

Everyone I knew respected these costumary laws, except of the powhitetrash children.

(ebook: 30, destaques meus)

Todo mundo que eu conhecia respeitava essas leis costumeiras, exceto as crianças brancas.

(ebook: 33, destaques meus)

A expressão "powhitetrash" ("poor white trash", ou, literalmente, "lixo branco e pobre”) é usada para se referir aos brancos pobres, marginalizados pela aristocracia da

Revista Letras,

Curitiba, UFPr,

n. 95 84-108, jan./jun. 2017. ISSN 2236-0999 (versão eletrônica) 
sociedade branca, os quais, no entanto, eram considerados como estando "um degrau acima dos afro-americanos na hierarquia social".7 Por sugerir um tom claramente pejorativo, a expressão foi simplesmente traduzida por “crianças brancas”, um sintagma evidentemente neutro. Em uma única passagem do livro traduzido, em que a mesma expressão é repetida no original, ela é traduzida, no máximo, como "branquelos". Em outro excerto da tradução, o efeito da busca do politicamente correto é ainda mais notável. A narradora descreve como era a Califórnia que conhecera quando criança. A passagem em destaque foi inteiramente omitida na tradução:

\section{Texto original}

The Asian population dwindled before my eyes. I was unable to tell the Japanese from the Chinese and was yet found no real difference in the national original of such sound as Ching and Chan or Moto and Kano.

As the Japanese disappeared, soundlessly and without protest, the Negroes entered with their loud jukeboxes, their just-released animosities and the relief of escape from Southern bonds. The Japanese area became San Francisco's Harlem in a matter of months.

(ebook: 224, destaques meus)

Tradução Paula Rosas - José Olympio Editora (1996)

A população asiática desapareceu, sem fazer ruído e sem protestar, os negros entraram com suas vitrolas automáticas, suas animosidades recém-abandonadas e o alívio de escapar dos elos Sulistas. A área japonesa tornou-se o Harlem de São Francisco em questão de meses.

(p. 194, destaques meus).

A narradora faz uma afirmação a respeito da dificuldade em perceber a diferença entre japoneses e chineses, o que, à editora e/ou tradutora, pareceu pouco aceitável para publicação, justificando-se, assim, a omissão da passagem inteira. A editora pode ter considerado que a manutenção do excerto, na tradução, poderia levar certos leitores a fazerem um julgamento negativo da autora. Poderiam lhe atribuir, no mínimo, falta de sensibilidade para as diferenças culturais entre duas minorias, o que seria incompatível com uma escritora negra que justamente lutou tantos anos contra a ausência de sensibilidade por parte dos brancos quanto às minorias negras. A passagem poderia ser vista como uma contradição que teria levado a editora a optar pela manutenção da coerência discursiva (em consonância, inclusive, com as traduções mais neutralizadoras de "powhitetrash").

7 Disponível em: http://www.hyperink.com/Key-Terms-And-Definitions-b1744a14. 
Amorim, L. M.

O Tempo e o $(E)$ vento: efeitos do tempo e do vento das mudanças em traduções de autobiografias de escritores afro-americanos
Entretanto, é possível fazer uma defesa da autora, no sentido de que, em vários momentos da narrativa, os limites entre a Maya Angelou, autora, e a narradora, Marguerite, são tênues e complexos. Há várias tentativas de construir relatos através dos olhos da menina Marguerite, ou seja, pelo ponto de vista que inclui os saberes próprios de uma criança. Assim, afirmações que, temporalmente, na atualidade, são mais sensíveis, suscitando uma crítica de natureza multicultural, na verdade, podem ser lidas como sendo percepções de uma criança, envolta por valores morais e éticos mais restritos à sua época e à sua idade. Desse modo, haveria uma diferença crucial entre a Maya Angelou de 1969 e a Marguerite da década de 30: a autora, como adulta, é muito mais consciente de aspectos éticos e morais que a menina Marguerite. Isso não impede, é claro, que a autora seja vista como um ser humano complexo, com suas limitações, que incluem, sim, contradições. Um dos elementos mais enriquecedores de uma autobiografia é justamente expor essas contradições, as fissuras que revelam seres humanos constituídos por arestas não aparadas, e não pela geometria perfeita das joias lapidadas. Nesse sentido, a diferença temporal que se caracteriza pela simulação da rememoração (com efeitos, inclusive, para a percepção do que seria antiético e contraditório) é reduzida para produzir uma identidade menos conflituosa, mais aceitável e mais alinhada com o presente enunciativo da narradora na condição de autora adulta. Algo semelhante ocorre também na próxima passagem, mas por meio de recursos linguísticos diferentes e envolvendo o tabu do estupro.

\section{d) $\mathrm{O}$ contraste entre o registro coloquial e o formal e a dimensão temporal na reconstrução do passado}

No processo de descrever o passado, especialmente quando trata da cena de um estupro, Maya Angelou recorre a descrições que são feitas a partir da perspectiva da autora enquanto criança, já que, por exemplo, há aspectos que a menina não compreende (ainda que a Angelou adulta saiba perfeitamente que é um abuso sexual de uma criança). Mas esse abuso, em si, não é percebido como tal pela criança no momento em que ele ocorre, de tal forma que, por exemplo, a menina tem a impressão, em dado momento, de que teria encontrado o seu verdadeiro pai, quando Freeman, seu padrasto, a abraça:

\section{Texto original}

"Now, I didn't hurt you. Don't get scared". He threw back the blankets and his 'thing' stood up like a brown ear of corn. He took my hand and said, 'Feel it.' It was mushy and squirmy like the inside of a freshly killed chicken. Then he dragged me on top of his chest with his left arm, and his right hand was moving so fast and his heart was beating so hard that I was afraid that we would die.

Revista Letras,

Curitiba, UFPR,

n. 95 84-108, jan./jun. 2017. ISSN 2236-0999 (versão eletrônica) 


\section{$[\ldots]$}

Finally he was quiet, and then came the nice part. He held me so softly that I wished he wouldn't ever let me go. I felt at home. From the way he was holding me I knew he'd never let me go or let anything bad ever happen to me. This was probably my real father and we had found each other at last. But then he rolled over, leaving me in a wet place and stood up.

(ebook: 79)

\section{$[\ldots]$}

It was true the bed was wet, but I knew I hadn't had an accident. Maybe Mr. Freeman had one while he was holding me. He came back with a glass of water and told me in a sour voice, 'Get up. You peed in the bed'. He poured water on the wet spot, and it did look like my mattress on many mornings.

\section{$[\ldots]$}

Having lived in Southern strictness, I knew when to keep quiet around adults, but I did want to ask him why he said I peed when I was sure he didn't believe that. If he thought I was naughty, would that mean that he would never hold me again? Or admit that he was my father? I had made him ashamed of me.

\section{Tradução Paula Rosas - José Olympio Editora (1996)}

— Eu não machuquei você. Não tenha medo. - Ele jogou as cobertas para o lado e sua 'coisa' ficou ereta como uma espiga de milho marrom. Ele segurou minha mão e disse: - Sinta.

Era mole como a parte interna de uma galinha recém-abatida. Então ele me arrastou para cima de seu peito com o braço esquerdo, sua mão direita movia-se tão depressa e seu coração batia tão forte, que tive receio de que ele morresse.

\section{$[\ldots]$}

Finalmente, ele ficou quieto e então veio a parte boa. Ele me abraçou com tanta suavidade, que eu desejei que ele nunca me soltasse. Eu me senti à vontade. Pelo modo como estava me segurando, eu sabia que ele nunca me soltaria nem deixaria nada de mau acontecer comigo. Provavelmente, este era meu verdadeiro pai e havíamos nos encontrado afinal. Mas então ele rolou na cama, deixando-me num lugar molhado e levantou-se. 
Amorim, L. M.

O Tempo e o $(E)$ vento: efeitos do tempo e do vento das mudanças em traduções de autobiografias de escritores afro-americanos $[\ldots]$

Era verdade que a cama estava molhada, mas eu sabia que eu não provocara o acidente. Talvez fosse o sr. Freeman ao me abraçar. Ele voltou com um copo de água e me disse com voz áspera: - Levante-se. Você fez xixi na cama.

Ele despejou água no ponto molhado, e pareceu realmente meu colchão em muitas manhãs.

\section{$[\ldots]$}

Tendo vivido na rigidez do Sul, eu sabia quando ficar calada em relação aos adultos, mas eu queria perguntar por que ele disse que eu fiz xixi quando eu tinha certeza que ele não acreditava nisso. Se acha que eu era má, isso significava que ele nunca mais me abraçaria de novo? Ou admitiria que era meu pai? Eu o fizera ficar envergonhado de mim.

(p.72-3, destaques meus)

Ao longo da descrição desses momentos, Maya Angelou não recorre a uma linguagem estritamente formal em inglês. Pelo contrário, algumas descrições oferecidas pela narradora, que se traveste de menina, são simples, marcadas pela ingenuidade de quem não consegue entender o que está ocorrendo. Obviamente, o texto em inglês, em si, não é uma representação direta do que uma criança de aproximadamente 08 anos falaria na realidade, já que o texto literário não é uma transcrição típica de uma fala, mas uma forma de simulação que busca aliar a linguagem de uma autora adulta à percepção de uma criança, dentro de certos limites de uma publicação. Assim, nessa passagem, pode-se entrever a busca pela inscrição de uma linguagem que se esforça por resgatar, no plano criativo da linguagem, a memória de Maya Angelou enquanto criança, não exatamente enquanto adulta. Obviamente, isso é uma estratégia discursiva, já que a autora não pode ter acesso direto à sua condição de criança no passado sem que isso seja, de algum modo, filtrado pela sua experiência de mulher adulta quando escreve o livro.

$\mathrm{Na}$ tradução, por outro lado, como destacado acima, observamos que, do ponto vista da variação linguística, a descrição de Maya Angelou criança é permeada por um léxico mais formal que aquele que se encontra no texto em inglês. Essa ligeira formalidade na tradução tende a lembrar o leitor de que quem conta a história, primordialmente, é a famosa narradora-autora, enquanto adulta, sem passar pela simulação do evento vivido pela criança recriada. É claro que, guardadas as diferenças, o ponto de vista semântico e lógico é preservado na tradução, mas nota-se uma diferença do ponto de vista estilístico que acaba por reafirmar, essencialmente, o papel central da autora-narradora a partir do lócus temporal da publicação do livro no Brasil. Isso não invalida, de modo algum,

Revista Letras,

Curitiba, UFPR,

n. 95 84-108,

jan./jun. 2017.

ISSN 2236-0999

(versão eletrônica) 
o trabalho da tradutora, mas a tentativa de se recriar o olhar memorialista da criança, quando, no original, a autora faz uso de um inglês relativamente mais simples, não é retomado na tradução. Certamente porque isso corresponde, no imaginário editorial construído acerca da autora, à ideia de que a fala da narradora, enquanto representação autobiográfica da escritora, deva se valer de uma linguagem dita "apropriada", mais próxima dos registros formais.

\section{Considerações finais}

Por meio dos contrastes propostos, tornou-se muito claro que as duas traduções da década de 1990 foram mais sensíveis às mudanças de valores éticos e morais que, em consonância com o multiculturalismo vigente, exerceram uma influência decisiva no modo com que as tradutoras, em conjunção com suas respectivas editoras, interpretaram determinadas passagens, incluindo descrições de natureza fenotípica de personagens negras, bem como situações que poderiam ser interpretadas, pelos leitores, como politicamente incorretas, e possivelmente incompatíveis com a imagem pública positiva que as editoras pretenderam reforçar para seus autores.

A diferença temporal entre a primeira e a segunda tradução da autobiografia de Richard Wright exerceu impactos distintos na forma em que a condição autobiográfica foi firmada nas duas reescritas: na primeira tradução, a autobiografia foi sensivelmente, em vários momentos, muito mais "ficcionalizada" no que diz respeito à linguagem descritiva, muito mais mediada pela sofisticação e subjetivação, do que a segunda tradução: no Brasil da década de 1940, os laços entre a fama de Wright e o seu reconhecimento pelos leitores eram francamente tênues, o que exigiu da editora focalizar a autobiografia muito mais como um evento literário, de caráter mais poético-simbólico, do que factual, criando-se mais a impressão de se estar contando a história do que seria a vida de qualquer criança negra em uma nação racista, do que a história da vida de um escritor negro bem sucedido. Posição claramente distinta da segunda tradução, realizada por Soares Neiva, que focaliza, na década de 90, a imagem pública já consagrada e consolidada de Richard Wright, o que a torna um processo de reescrita afinada com uma linguagem mais ordinária e próxima de uma simulação mais realista dos eventos narrados.

A tradução da autobiografia de Maya Angelou não deixa de se firmar como autobiografia, à semelhança da tradução de Black Boy, feita por Soares Neiva. No entanto, o que se percebeu, com as análises, é que a autobiografia traduzida por Paula Rosas tende a focalizar a narrativa muito mais em torno da própria autora Maya Angelou adulta, através de uma simulação que torna o tempo presente a ancoragem cronológica fundamental a partir da qual a história deverá ser contada. Assim, aspectos que, na narrativa em inglês, ajudam a produzir uma simulação que inscreve a voz da narradora na perspectiva do 
Amorim, L. M.

O Tempo e o $(E)$ vento: efeitos do tempo e do vento das mudanças em traduções de autobiografias de escritores afro-americanos passado, enquanto criança, são atenuados ou até mesmo eliminados na tradução (como, por exemplo, o emprego de inglês afro-americano vernacular nas falas de personagens variados, ou passagens mais coloquiais da fala da menina Marguerite, ou mesmo observações feitas pela garota que poderiam soar "politicamente incorretas" nos dias atuais.). Na tradução, assim, procurou-se, de certa forma, produzir uma coerência interna que fosse compatível com uma noção de autobiografia fundamentada, sobretudo, na percepção que o leitor tem ou pode ter sobre a autobiografia com base nos valores que a autora, à época da publicação da tradução, conseguiu congregar positivamente na afirmação de sua identidade pública ao longo dos anos.

Este trabalhou buscou contribuir com uma reflexão sobre as relações entre tradução e reenunciação na reescrita de autobiografias de autores afro-americanos, tendo em vista a passagem do tempo e seus efeitos sobre a escrita tradutória e sobre a reimaginação que ela promove acerca de eventos biográficos. É em consonância com o espírito das reflexões sobre o tempo e o vento das mudanças que ele acarreta, que foi proposto o título deste artigo: um jogo de palavras que remete ao romance magistral de Érico Veríssimo, O Tempo e o Vento, obra que nos permite refletir sobre as relações entre a passagem do tempo e o modo como ele é "temperado" pela ação do vento, metaforicamente entendido como o conjunto do(s) próprio(s) evento(s) que, ao "temperarem" a dimensão histórica-temporal do Brasil, também "temperam” as vidas de diferentes gerações de famílias no Rio Grande do Sul. É interessante refletir não somente como a tradução é impactada pelo seu imbricamento com o tempo, mas, sobretudo, como a própria tradução exerce um papel fundamental em "temperar" o tempo, com a força e a delicadeza imponderáveis dos diferentes (e)ventos da vida. 


\section{Referências}

ANGELOU, Maya. I know why the caged bird sings. London: Hachette Digital, 2010. E-book.

. Eu sei por que o pássaro canta na gaiola. Tradução de Paula Rosas. Rio de Janeiro: José Olympio, 1996.

DARIN, Leila. Conexões pouco exploradas entre escrita autobiográfica e tradução, TradTerm, v.24, p.65-82, 2014. Disponível em: <ttp://www.revistas. usp.br/tradterm/article/view/96131/95352>. Acesso em: Jan 2015.

DERRIDA, Jacques. Posições. Tradução de Tomaz Tadeu da Silva. Rio de Janeiro: Autêntica, 2001.

LEFEVERE, Andre. Tradução, reescrita e manipulação da fama literária. Tradução de Cláudia Matos Seligmann. Bauru: Edusc, 2007.

LEJEUNE, Philippe . O pacto autobiográfico: de Rousseau à Internet. Organização de Jovita M. G. Noronha. Tradução de Jovita M. G. Noronha e Maria I. C. Guedes. Belo Horizonte: Editora UFMG, 2008.

SMITHERMAN, G. Black talk: words and phrases from the hood to the amen corner. Revised edition. Boston, New York: Houghton Mifflin Company, 2000 .

WRIGHT, Richard. Black boy (American Hunger): a record of childhood and youth. New York: Harper Collins, 2009. E-book.

Negrinho: recordações da infância e da juventude. Tradução de Wilson Velloso. Editora Companhia Nacional, 1946.

Black boy: infância e juventude de um negro americano.

Tradução de Aurora Soares Neiva. Rio de Janeiro: Espaço e Tempo, 1993.

Submetido em: 05/07/2016

Aceito em: 24/12/2016 